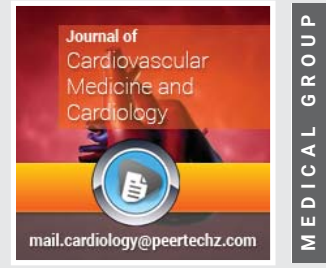

\section{The role of cardiac rehabilitation in aviation medicine}

\section{Jeffrey Dwyer*}

Department of Cardiology, Kaiser Permanente Medical Center, 975 Sereno drive, Vallejo, CA 94533, USA
Received: 18 April, 2020

Accepted: 11 June, 2020

Published: 12 June, 2020

*Corresponding author: Jeffrey Dwyer, Ph. D, Department of Cardiology, Kaiser Permanente Medical Center, 975 Sereno drive, Vallejo, CA 94533, USA,

E-mail: Jeff.dwyer@Kp.org

Keywords: Rehabilitation of pilots; Aviation medicine; Flying

https://www.peertechz.com

Check for updates

\title{
Abstract
}

After a cardiovascular illness, an aviation license becomes invalid until the pilot obtains a special issuance medical certificate from the US Federal Aviation Agency (FAA) affirming successful medical treatment and rehabilitation. Many pilots attempt to regain health and fitness without the benefit of guidance from cardiac rehabilitation practitioners and, therefore, fail to satisfy FAA requirements. I the US, in 2016, more than 10,000 pilots with cardiovascular disorders were denied special issuance of a medical certificate. For many of these pilots with heart disease, participation in a cardiac rehabilitation program may have proven essential for successful completion of a rigorous medical examination that satisfied FAA requirements. This article highlights specific assistance provided by a cardiac rehabilitation program developed for pilots. Program objectives are; 1). the highest possible outcome, 2). establish a safe and effective independent exercise program, 3). obtain measures of compliance and success with an independent exercise program, 4). document tolerance of medications and ensure that the medication regimen complies with FAA guidelines, 5). document stability of the serum glucose in diabetic patients engaged in rigorous, prolonged exercise, and 6). prepare the patient for performance of a diagnostic treadmill test in which $100 \%$ HRmax must be achieved. It is estimated that fewer than $15 \%$ of pilots with heart disease utilize services offered by cardiac rehabilitation practitioners.

\section{Introduction}

U.S. Federal Aviation Regulations (FARs) mandate the Federal Aviation Administration (FAA) to protect the public from pilots whose ability to operate aircraft may be impaired by illness or medical problems including the adverse effects of common medications $[1,2]$. The public, and the pilot, are afforded protection by a Federal requirement that all pilots must obtain a medical certificate biannually from an FAAdesignated medical examiner. If a pilot fails to meet rigid health standards, renewal of the certificate is denied and a license to operate aircraft becomes invalid. If the pilot is diagnosed with a cardiovascular illness or disorder, the medical certificate is immediately revoked. These medical diagnoses include signs of coronary insufficiency (angina), Myocardial Infarction (MI), Coronary Artery Bypass Graft (CABG) surgery, valve replacement (AVR, MVR) or repair, Pacemaker Implantation (PM), Cardiomyopathy (CMP), Heart Failure (HF), and Percutaneous Coronary Intervention (PCI) [3]. Heart transplantation is also a basis for revocation of the medical certificate [4] although, in 2016, five pilots held special issuance medical certificates.
After a cardiovascular illness, flight privileges may be restored if the pilot can provide evidence of successful medical treatment and attain a high level of fitness. Special issuance of a medical certificate always includes the stipulation that the pilot present for a lengthy and rigorous clinical evaluation every 6-12 months.

In a typical year, the US FAA processes more than 400,000 pathological records of pilots and considers more than 35,000 requests for special issuance of an aviation medical certificate. In 2016, 560,152 special issuance medical certificates were held by US pilots with a wide range of medical problems. In that year, more than 10,000 applications from pilots with heart disease were denied (personal communication). More than $90 \%$ of denials were due to inadequate medical information submitted or failure to achieve rigid FAA standards in an exercise test or other medical exam.

The application process for a special issuance medical certificate is complicated and most pilots face a bewildering set of Federal regulations alone while they attempt to gather medical records and other information, often from two more 
medical facilities. Moreover, many patients attempt to regain health and fitness without the benefit of professional guidance and proven methods of rehabilitation, leading to outcomes that are less than optimal and failure to gain a special issuance medical certificate. For many patients, a formal cardiac rehabilitation program may prove essential in their quest to regain sufficient health and fitness to resume flying.

\section{FAA requirements}

After a cardiac illness, the FAA requires a waiting period of six months, from the date of diagnosis or event, before a pilot may begin gathering medical information and undergo tests in support of an application for special issuance of a medical certificate. Table 1 lists the information required. In addition to hospital records, recent labs, and exercise test results, the applicant must submit a report, by an internal medicine specialist or cardiologist that includes an assessment of the pilot's current health status, a review of all pertinent medical records, and a prognosis for incapacitation during the next 6-12 months. If the applicant seeks a Class I or unlimited Class II medical certificate (Table 2), required for commercial aviation activity, he/she must submit a report of a coronary angiogram performed no sooner than 6 months after the event that resulted in revocation of the medical certificate. If the pilot declines to undergo cardiac catherization, a limited Class 2 certificate may be issued if the pilot can meet FAA standards in an exercise test combined with radionuclide imaging as an index of myocardial perfusion.

Patients who have implanted pacemakers must submit results of a 24-hour ambulatory ECG study and a minimum of six monthly pacemaker function reports obtained by computer interrogation of the device. These requirements are added to those listed in Table 1. In many cases, pilots must pay for these tests, including coronary angiogram, out of pocket since most health insurance plans do not cover tests required for resumption of non-vocational aviation activities.

\section{Cardiac Rehabilitation Services}

Cardiac rehabilitation programs that conform to the standards of the American Association for Cardiovascular and Pulmonary Rehabilitation (AACVPR) provide essential interventions to limit the physiologic and psychological effects of a cardiac illness, reduce the risk of sudden death and myocardial infarction, control cardiac symptoms, stabilize or reverse the atherosclerotic process, and enhance the psycho-social and vocational status of patients [5]. These programs provide medical evaluation, supervised and ECGmonitored exercise sessions, cardiac risk factor modification interventions, education experiences, and counseling that may be essential if a pilot is to satisfy FAA requirements for special issuance of an aviation medical certificate.

The principle goals of cardiac rehabilitation programs designed for pilots are; 1 ). Achieve the highest possible outcome of the rehabilitation process with respect to guidelines of the AACVPR [5], 2). Establish a safe and effective independent exercise program, 3). Obtain measures of compliance and
Table 1: US FAA requirements for special issuance of a medical certificate after a cardiac illness.

\section{ALL CLASSES:}

Hospital records: History and Physical exam upon admission, reports of consultants, surgical reports and special procedures (e.g., echocardiogram), daily progress notes by physicians, ECG's, coronary angiogram report, discharge summery.

Laboratory data: Fasting serum glucose, fasting lipid panel, hemoglobin and hematocrit, $\mathrm{Hb}-\mathrm{A} 1 \mathrm{C}$, coagulation studies.

Exercise test: complete a maximal stress test to $100 \%$ predicted HRmax (preferably using the Bruce protocol); submit 12-lead ECG performed in sitting, standing, and post-hyperventilation, and in each stage of exercise and each minute of 5-minute recovery

Cardiovascular evaluation: A complete clinical evaluation with consideration of family history and personal history of cardiovascular disease including risk factors; review of all pertinent labs, medication use, tolerance of medications; assessment of the patient's motivation for change, prognosis for incapacitation.

\section{CLASS I and II}

Coronary angiogram: Six months post-event; all reports and actual films.

Exercise test: a maximal stress test to $100 \%$ predicted HRmax with radionuclide imagining.

Table 2: Classes of US civilian aviation medical certificates.

\begin{tabular}{|c|c|c|c|}
\hline Class & I & II & III \\
\hline $\begin{array}{c}\text { Frequency of } \\
\text { recertification, } \\
\text { months }\end{array}$ & 6 & 12 & 12 \\
\hline Required for & $\begin{array}{c}\text { Pilots in } \\
\text { command } \\
\text { of most } \\
\text { passenger } \\
\text { aircraft }\end{array}$ & $\begin{array}{c}\text { All other aviators who derive } \\
\text { income from operating aircraft; } \\
\text { includes air traffic controllers }\end{array}$ & $\begin{array}{c}\text { Pilots who operate } \\
\text { US register } \\
\text { aircraft for non- } \\
\text { remunerative } \\
\text { personal use }\end{array}$ \\
\hline Comments & $\begin{array}{c}\text { Strictest } \\
\text { medical } \\
\text { Standards }\end{array}$ & $\begin{array}{c}\text { Includes copilots flight } \\
\text { engineers of passenger aircraft, } \\
\text { air freight, corporate pilots, crop } \\
\text { dusters, flight instructors }\end{array}$ & $\begin{array}{c}\text { Least strict medical } \\
\text { standards }\end{array}$ \\
\hline
\end{tabular}

success with the independent exercise program, 4). Document tolerance of medications and ensure that the medication regime is acceptable to the FAA, 5). Document stability of the serum glucose in diabetic patient engaged in rigorous, prolonged exercise, and 6). Prepare the patient for performance of a treadmill test in which $100 \%$ age-predicted HR maximum (HRmax) is achieved without symptoms of cardiovascular distress.

Dwyer [6], reported details of an aviation-directed cardiac rehabilitation program developed at the Kaiser Permanente Medical Center in Vallejo, CA. That report includes case histories of three pilots who resumed commercial and private aviation after CABG and pacemaker implantation.

The Kaiser program enrolls pilots for six months, but participation may be extended if the pilot fails to achieve $100 \%$ HRmax in a treadmill test, without symptoms or ECG changes indicating ischemia, frequent ventricular ectopy, or dysrhythmia such as paroxysmal atrial fibrillation or SVT. The initial rehabilitation period spans 9-12 weeks and includes 2-3 visits per week. ECG-monitored exercise includes treadmill, leg cycle, arm cycle, elliptical, and simulated stair climb activity. Pilots also perform strengthening and flexibility exercises at designated stations located throughout the facility. 
Each exercise session stresses endurance with up to 50 minutes of aerobic activity performed. Patients are taught selfassessment techniques based on empirically determined target heart rates and the Borg scale for rating of perceived exertion (RPE). Patients also learn how to down-regulate intensity if unusual fatigue or an uncomfortable level of ventilatory effort occurs, and appropriate warm-up and cool-down activity.

After 9-12 weeks of ECG-monitored, clinic-based exercise sessions, most pilots are transitioned into an independent exercise program, preferably at a gym. They return to the cardiac rehab clinic 1-2 times each month to insure progress with the independent exercise program and revise target intensities. During the fifth month of rehabilitation, the pilot's cardiologist is informed of the patient's status regarding exercise capacity and readiness for a maximal treadmill test performed off all HR-attenuating medications.

\section{Preparation for Exercise Testing}

No sooner than six months from the date of diagnosis with a cardiovascular disease, the FAA requires that a pilot undergo a diagnostic treadmill test in which $100 \%$ of the agepredicted HR maximum is achieved and a minimum of Stage III of the Bruce protocol completed while all HR-attenuating medications are held. For many patients, exercising on a steeply inclined treadmill at a pace far above that used in rehabilitation exercise sessions may be physically and psychologically stressful. Therefore, special exercise sessions are conducted to familiarize the patient with the demands of the Bruce treadmill protocol. Several exercise sessions may be needed to gain skill and confidence, recondition leg muscles, and become comfortable with the fatigue and ventilatory stress evoked by Stage III or IV of the Bruce protocol. These preparatory exercise sessions typically include walking at a pace that varies from 2.5 to $4.2 \mathrm{mph}$ with inclines from 6 to $12 \%$ for periods of 1 to 3 minutes. A closely monitored trial of exercise at Bruce Stage I and II is used to discern deficits in skill and endurance, and the patient's comfort on a steeply inclined treadmill.

While working toward the goals listed above, patients typically achieve significant risk factor improvements such as good control or resolution of hypertension, a normalized lipid panel, and reduction of body mass index to within normal limits. Fasting glucose and glycated hemoglobin (HbA1c) are usually improved by diabetics who participate in this intense rehabilitation process. Some patients reduce or eliminate dependence upon certain medications or combinations of medications that may not be acceptable to the FAA $[3,6]$.

The lengthy process of gathering material describing the applicant's medical status may be hindered by several pitfalls and problems. Early in the rehabilitation course, it is essential that the patient's medication regimen be carefully reviewed with respect to FAA guidelines. This affords time to revise the medication regimen to ensure compliance with FAA requirements and document drug tolerance by assessment of blood pressure and heart during long periods of exercise at the prescribed target intensity and during a recovery period $[3,7]$.
Cardiac rehabilitation clinicians may provide the pilot, the referring physician, and the FAA with information that comprises essential support for a successful application process. Table 3 lists information that would not be available for inclusion in an application for special issuance of a medical certificate if the pilot did not participate in a cardiac rehabilitation program.

Table 3: Information available in a report from a cardiac rehabilitation practitioner describing a pilot's status upon completion of a rehab program.

Baseline Data: Resting BP, HR, rhythm per ECG; orthostatic or tilt table evaluation; Adverse effects of medication observed in exercise.

Education/Behavioral Modification: Participation in and outcomes of smoking cessation therapy, diabetes management classes; programs for body weight control, stress management, lipid management.

Exercise Tolerance: Training intensity (METs) in the rehab clinic; rating of perceived exertion (RPE), heart rate and blood pressure responses on all medications, rhythm per ECG; mode and duration of rehab activities; incidence of signs or symptoms of undue cardiac distress; indices of participation; measures of improvement such as elevation or elimination of a symptom threshold, endurance capacity, and indications for upward revision of target intensity.

Home Exercise Program: Exercise prescription for an independent exercise program (mode, target intensity, frequency, duration); measures of compliance, improvement in endurance capacity.

\section{Discussion}

The US FAA database indicates that on December 31, 2016, 8,932 pilots with a history of CABG, MI, or PCI held valid medical certificates. On that date, Class I certificates were held by 1,963 commercial pilots while 5.953 held Class III certificates principally for private aviation. On that date, only 101 pilots with implanted pacemaker held a Class I certificate. Class II and III certificates were held by 78 and 361 pilots, respectively. More than 58,000 pilots with hypertension, treated with medication, held special issuance medical certificates. In 2016, over 10,000 applications for a medical certificate, submitted by pilots with documents heart disease, were denied.

There is no data available to determine how many successful applicants had attended a cardiac rehabilitation program. There is evidence, however, that participation in a cardiac rehabilitation program results in favorable outcomes in pilots, including earlier resumption of premorbid lifestyle and successful return to work as a member of a flight crew [6].

Several authors have reviewed the role of invasive procedures, such as PCI and CABG surgery, and pacemaker implantation, in the management of pilots with heart disease [8-14], but none specifically emphasize the role of cardiac rehabilitation. Moreover, aviation medical examiners do not routinely inform patients of the benefits of cardiac rehabilitation programs. This is remarkable in view of evidence that risk factor modification successes in smoking cessation and reduction of hypertension results in lower risk of future cardiac events among pilots [11-15]. Reviews of the incidence of heart disease among US military aviators [9,10] clearly indicate that cardiovascular risk factors that may be improved by interventions that include regular exercise. 
The US Department of Health and Human Services estimates that, in the general population, fewer than $20 \%$ of eligible patients with coronary artery disease participate in a formal cardiac rehabilitation program $[15,16]$. It is likely that an equally low number of pilots have utilized cardiac rehab services as a means of becoming eligible for a special issuance medical certificate.

\section{Conclusion}

Cardiac rehabilitation programs offer a wide range of services that may prove essential to pilots in their quest to regain sufficient health and fitness to be eligible for special issuance of a medical certificate after CABG surgery, PCI, or pacemaker implantation. It is likely that these services are vastly under-utilized by aviation medicine practitioners and their patients.

\section{References}

1. Federal Aviation Regulations. US Government Printing Office 2020.

2. Engelberg AL, HL Gibbons, TC Dodge (1986) A review of the medical standards for civilian airmen. JAMA 25: 1589-1599. Link: https://bit.ly/2YOv9MH

3. Office of Aviation Medicine. Guide for Medical Examiners (2020) US Department of Transportation, Federal Aviation Administration Link: https://bit.ly/2AofwCa

4. McGiffin D, DC Naftel, Spann JL, Kirklin JK, Young JB, et al. (1998) Risk of death or incapacitation after heart transplantation, with particular reference to pilots. J Heart Lung Transpl 17: 497-504. Link: https://bit.ly/31BAclc

5. American Association of Cardiovascular and Pulmonary Rehabilitation Guidelines for Cardiac Rehabilitation and Secondary Prevention Programs. $6^{\text {th }}$. Champaign, IL: Human Kinetics 2021. Link: https://bit.ly/2NIEgb5
6. Dwyer J (2001) Return to Flight Status After Cardiac rehabilitation: Three Case Histories. J Cardiopulmon Rehabil 21: 280-287. Link: https://bit.ly/3dO9HeV

7. Osswald S, Mikles R, Nixon W, Celio P (1996) Review of cardiac events in USAF aviators. Aviat Space Environ Med 67: 1023-1027. Link: https://bit.ly/2BRR5xo

8. Khan MA, Amroliwalla FK (1996) Flying status and coronary revascularization procedures in military aviators. Aviat Space Environ Med 67: 165-170. Link: https://bit.ly/3dPtpH1

9. Shiu MF (1988) Percutaneous transluminal coronary angioplasty and flying status. Europ Heart J 101-105. Link: https://bit.ly/2ZmnxQq

10. Hoiberg A (1985) Cardiovascular disease among US Navy pilots. Aviat Space Environ Med 56: 397-402. Link: https://bit.ly/2YMgUI8

11. Chaitman BR, Davis KB, Dodge HT, Fisher LD, Pettinger M, et al. (1986) Should airplane pilots be eligible to resume active flight status after coronary bypass surgery?: A CASS registry study. J Am Coll Cardiol 8: 1318-1324. Link: https://bit.ly/38hIS1k

12. Hammond IW, Lee ET, Davis AW, Booze CF (1984) Prognostic factors related to survival and complication-free times in airmen medically certified after coronary surgery. Aviat Space Environ Med 55: 321-331. Link: https://bit.ly/31FF60q

13. Toff WD, Camm AJ (1988) Implanted devices and aviation. Europ Heart J 9: 133-138. Link: https://bit.ly/3gk3IzV

14. Toff WD, Edhag OK, Camm AJ (1992) Cardiac pacing and aviation. Europ Heart 13: 162-175. Link: https://bit.ly/2ZpNMph

15. Agency for Health Care Policy and Research (1995) Clinical Practice Guideline 17: Cardiac Rehabilitation. US Department of Health and Human Services publication 96-0672.

16. Thomas RJ (2007) Cardiac Rehabilitation/Secondary Prevention. A Raft for the rapids; Why have we missed the boat? Circ 116: 1644-1646. Link: https://bit.ly/2ZqOyEa
Discover a bigger Impact and Visibility of your article publication with Peertechz Publications

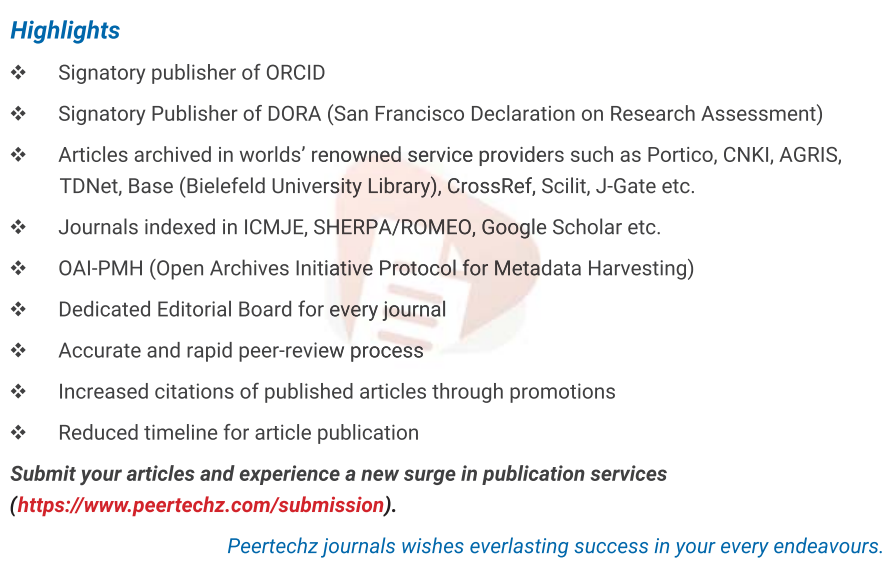

Copyright: (c) 2020 Dwyer J. This is an open-access article distributed under the terms of the Creative Commons Attribution License, which permits unrestricted use, distribution, and reproduction in any medium, provided the original author and source are credited. 